\title{
The effect of Ramadan fasting during pregnancy on perinatal outcomes: a systematic review and meta-analysis
}

Jocelyn D. Glazier ${ }^{1}$, Dexter J. L. Hayes ${ }^{1}$, Sabiha Hussain', Stephen W. D'Souza', Joanne Whitcombe², Alexander E. P. Heazell ${ }^{1}$ and Nick Ashton ${ }^{3^{*}}$ (D)

\begin{abstract}
Background: Although exempt, many pregnant Muslim women partake in the daily fast during daylight hours during the month of Ramadan. In other contexts an impoverished diet during pregnancy impacts on birth weight. The aim of this systematic review was to determine whether Ramadan fasting by pregnant women affects perinatal outcomes. Primary outcomes investigated were perinatal mortality, preterm birth and small for gestational age (SGA) infants. Secondary outcomes investigated were stillbirth, neonatal death, maternal death, hypertensive disorders of pregnancy, gestational diabetes, congenital abnormalities, serious neonatal morbidity, birth weight, preterm birth and placental weight.

Methods: Systematic review and meta-analysis of observational studies and randomised controlled trials was conducted in EMBASE, MEDLINE, CINAHL, Web of Science, Google Scholar, the Health Management Information Consortium and Applied Social Sciences Index and Abstracts. Studies from any year were eligible. Studies reporting predefined perinatal outcomes in pregnancies exposed to Ramadan fasting were included. Cohort studies with no comparator group or that considered fasting outside pregnancy were excluded, as were studies assuming fasting practice based solely upon family name. Quality of included studies was assessed using the ROBINS-I tool for assessing risk of bias in non-randomised studies. Analyses were performed in STATA.
\end{abstract}

Results: From 375 records, 22 studies of 31,374 pregnancies were included, of which 18,920 pregnancies were exposed to Ramadan fasting. Birth weight was reported in 21 studies and was not affected by maternal fasting (standardised mean difference [SMD] $0.03,95 \% \mathrm{Cl} 0.00$ to 0.05). Placental weight was significantly lower in fasting mothers (SMD $-0.94,95 \% \mathrm{Cl}-0.97$ to -0.90 ), although this observation was dominated by a single large study. No data were presented for perinatal mortality. Ramadan fasting had no effect on preterm delivery (odds ratio 0.99, 95\% Cl 0.72 to 1.37 ) based on 5600 pregnancies (1193 exposed to Ramadan fasting).

Conclusions: Ramadan fasting does not adversely affect birth weight although there is insufficient evidence regarding potential effects on other perinatal outcomes. Further studies are needed to accurately determine whether Ramadan fasting is associated with adverse maternal or neonatal outcome.

Keywords: Birth weight, Fasting, Placenta, Pregnancy, Ramadan

\footnotetext{
* Correspondence: nick.ashton@manchester.ac.uk

${ }^{3}$ Division of Cardiovascular Sciences, Faculty of Biology, Medicine and Health,

University of Manchester, 3rd Floor Core Technology Facility, 46 Grafton

Street, Manchester M13 9NT, UK

Full list of author information is available at the end of the article
}

(c) The Author(s). 2018 Open Access This article is distributed under the terms of the Creative Commons Attribution 4.0 International License (http://creativecommons.org/licenses/by/4.0/), which permits unrestricted use, distribution, and reproduction in any medium, provided you give appropriate credit to the original author(s) and the source, provide a link to the Creative Commons license, and indicate if changes were made. The Creative Commons Public Domain Dedication waiver (http://creativecommons.org/publicdomain/zero/1.0/) applies to the data made available in this article, unless otherwise stated. 


\section{Background}

During the month of Ramadan, healthy adult Muslims abstain from eating and drinking from sunrise until sunset. This represents a form of intermittent fasting where both the quantity and quality of food eaten are altered [1]. Although pregnant Muslim women are exempt from fasting, evidence suggests that up to $90 \%$ partake in Ramadan fasting for at least part of the month [2, 3], being keen to share the cultural experience with their families. The estimate of 230 million Muslim women of childbearing age worldwide [4], with a fertility rate averaging 3.1 children per woman [4], leads to the potential for up to 535 million babies in each generation to be exposed in utero over Ramadan to a repeated cyclical pattern of maternal intermittent fasting.

Exposure to a restricted or sub-optimal diet during pregnancy affects fetal development and has life-long health impacts on the offspring [5]. Low birth weight and altered neonatal growth trajectories are associated with an increased risk of cardiovascular disease, diabetes [5], obesity [6] and impaired cognitive function [7]. Preterm delivery and reduced birth weight are more prevalent in women who eat less frequently while pregnant [8], suggesting that pregnant women who fast during Ramadan may be more likely to give birth to premature or underweight babies.

Although the impact of Ramadan fasting during pregnancy on the health of the child has been investigated [9-13], individual studies show conflicting results and sample sizes are often too small to allow evaluation of serious, but infrequent, outcomes. Furthermore, the timing of exposure to maternal fasting during Ramadan may affect the outcome [14], yet the trimester of fetal exposure to fasting is generally poorly defined in studies. Although fasting could arise at any pregnancy stage, occurrence early in the first trimester seems most likely as the mother may be unaware that she is already pregnant. Fasting during the first trimester has been reported to be associated with reduced birth weight [15], whereas placental weight, another predictor of health outcomes in offspring [16], is reportedly lower if the mother fasted during the second or third trimester [17].

Muslim women may seek advice from health practitioners regarding the safety of Ramadan fasting; however the current information available to pregnant women is contradictory [18] and clear guidance is lacking. Therefore, available evidence regarding associations between Ramadan fasting and pregnancy outcomes needs to be evaluated.

The aim of this systematic review and meta-analysis was to determine the effects of maternal intermittent fasting during Ramadan on a range of pregnancy outcomes.

\section{Methods}

The systematic review and meta-analysis is reported in accordance with PRISMA guidelines [19]; the review protocol was registered with the International Prospective Register of Systematic Reviews (PROSPERO) on 8 July 2016 (CRD42016041949).

\section{Eligibility criteria, information sources, search strategy} Searches were carried out in EMBASE, MEDLINE, CINAHL, Web of Science, Google Scholar, the Health Management Information Consortium (HMIC) and Applied Social Sciences Index and Abstracts. In order to reduce publication bias, searches were also carried out in the Centre for Reviews and Dissemination databases, ProQuest and EThOS to uncover any relevant unpublished studies and grey literature. Reference lists of eligible studies were checked for other potentially eligible studies for inclusion. The search was not limited by dates but was limited to English-only publications. All searches were updated on 11 April 2018. See Additional file 1 for the EMBASE search strategy. Searches were performed by JW, SH and DH.

We included observational studies which reported either primary or secondary outcomes in pregnancies that were exposed to intermittent fasting during Ramadan compared to unexposed pregnancies. Randomised controlled trials or cluster randomised controlled trials were also eligible. Cohort studies with no comparator group (which only reported an outcome of interest in women who fasted during pregnancy) were excluded. If studies assumed fasting practice based solely upon ethnic group or family name then they were excluded as this was deemed to be unreliable. Studies were not excluded based on their geographical location or the timing of fasting with regard to trimester of pregnancy.

Studies were included if they reported a relevant pregnancy outcome in women who intermittently fasted during their pregnancy. The exposure of interest was intermittent fasting during the month of Ramadan during any stage of pregnancy. Studies looking at fasting during any other time period (prior to conception, postnatal period) were excluded.

Primary outcomes for this study were: perinatal mortality (the death of a baby before birth or during the first week of life), preterm birth (before 37 weeks of pregnancy) and small for gestational age (SGA) infants (as defined by each study or below the tenth centile for gestational age). Secondary outcomes were: stillbirth (the death of a baby before birth after 20 weeks' gestation), neonatal death (the death of a baby during the first 28 days of life), maternal death (the death of the mother during pregnancy or the first 6 weeks postnatally), hypertensive disorders of pregnancy, gestational diabetes, congenital abnormalities (structural abnormalities of the fetus), serious neonatal morbidity, birth weight (continuous variable), low birth weight $(<2500 \mathrm{~g})$, very low birth weight $(<1500 \mathrm{~g})$, extremely preterm birth ( $<28$ weeks gestation) and placental weight (continuous variable). 


\section{Data extraction}

After removal of duplicates, all citations were screened for relevance using the full citation, abstract and indexing terms. Relevant studies were assessed for eligibility by two out of four reviewers (SH, DH, JG and SDS) according to the pre-specified inclusion and exclusion criteria, and where possible full manuscripts were obtained. Final decisions were made by two reviewers independently and a third (AH or NA) consulted to resolve any issues where necessary. Where data were missing or incomplete, attempts were made to contact the authors for clarification.

\section{Assessment of risk of bias}

Included studies were assessed using the Risk Of Bias In Non-randomised Studies - of Interventions (ROBINS-I) tool [20], which categorises risk of bias as low, moderate, serious, critical and unclear, and the risk of bias category for each study was reported; if a study's risk of bias was categorised as serious, critical or unclear, the effect of removing this study was tested and the relevant outcome(s) reported.

\section{Data synthesis}

Meta-analysis was performed in STATA (Version 14) [21] using the metan [22] and metabias [23] commands. Random effects meta-analysis was used in anticipation of heterogeneity due to differences in study design.

For continuous variables (birth weight and placental weight), standardised mean differences (SMD) (Hedges' g) with 95\% confidence intervals were calculated. For binary variables (low birth weight and preterm delivery), odds ratios and 95\% confidence intervals were calculated. The $I^{2}$ statistic was calculated; this is derived from Cochran's chi-squared statistic $Q$ and is used to describe the percentage of between-study variation that is attributable to variability in the true exposure effect [24]. An $I^{2}$ value of $0-30 \%$ was classified as low, $31-60 \%$ as moderate, 61-90\% substantial and 91-100\% considerable [25]. Funnel plots were created to test for small-study effects.

Where studies presented continuous data grouped by trimester in which fasting took place, length of fasting or stratified by other measures (e.g. fetal sex), then averages were taken to obtain overall means and standard deviations. Where outcome data were available by fasting trimester then data were stratified by trimester and the effect of this was investigated.

\section{Results}

\section{Study selection}

The search strategy identified 375 records (Fig. 1). After duplicates were removed 118 papers were screened on the basis of their titles and abstracts. Forty papers were

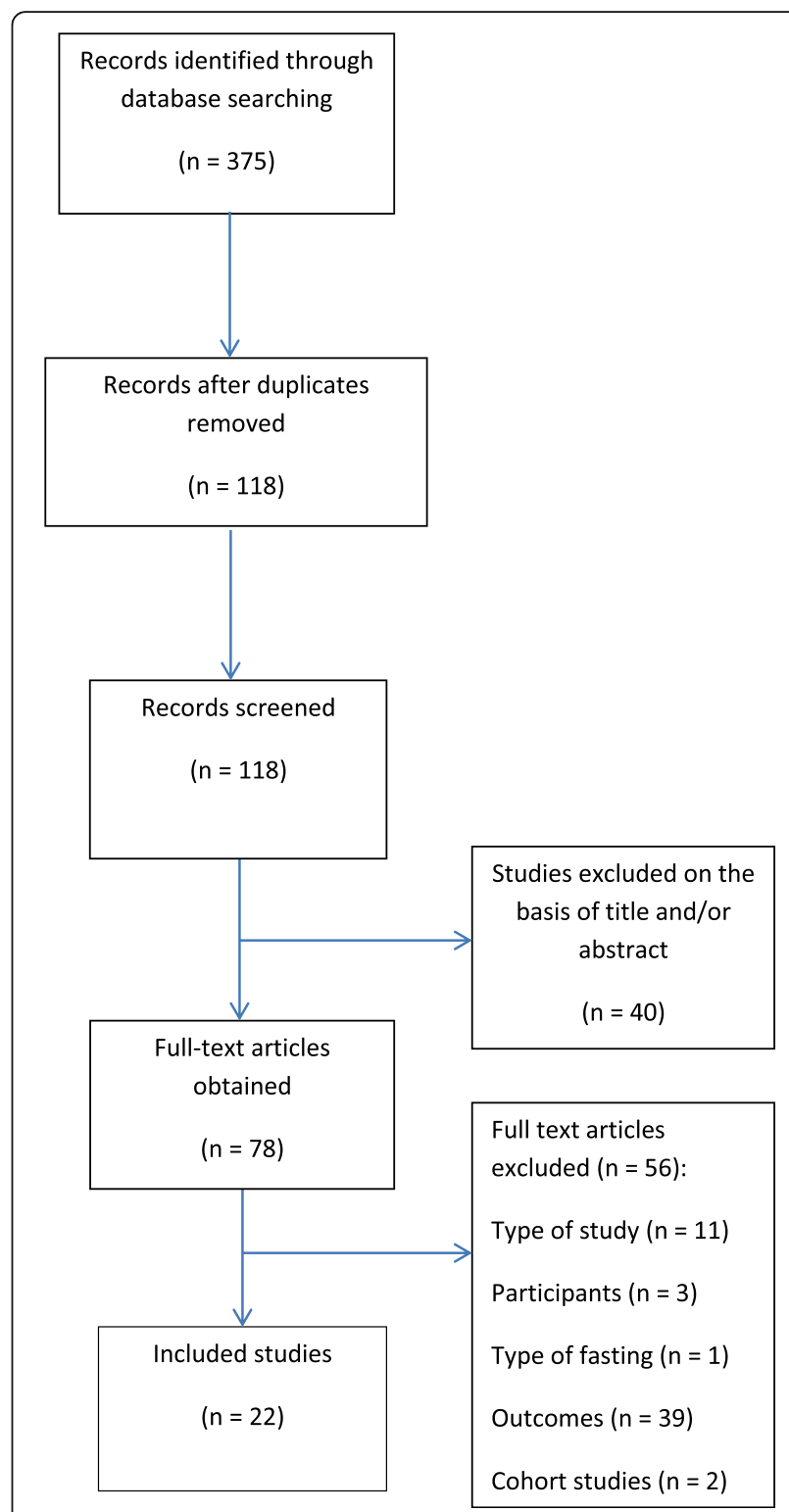

Fig. 1 PRISMA diagram of included studies. Flow chart showing study selection

excluded on this basis, resulting in 78 papers to be evaluated using their full text. After exclusions, 22 studies of 31,374 pregnancies were included in the final analysis.

\section{Study characteristics}

Seven studies reported data for at least one of the co-primary outcomes (perinatal mortality, SGA infants and preterm birth) and all but one study [9] reported data on at least one secondary outcome (Table 1). Six studies were judged to be at moderate risk of bias; the other 16 were determined to be at low risk (Table 2). Heterogeneity for outcomes ranged from 0 to $98.5 \%$. 


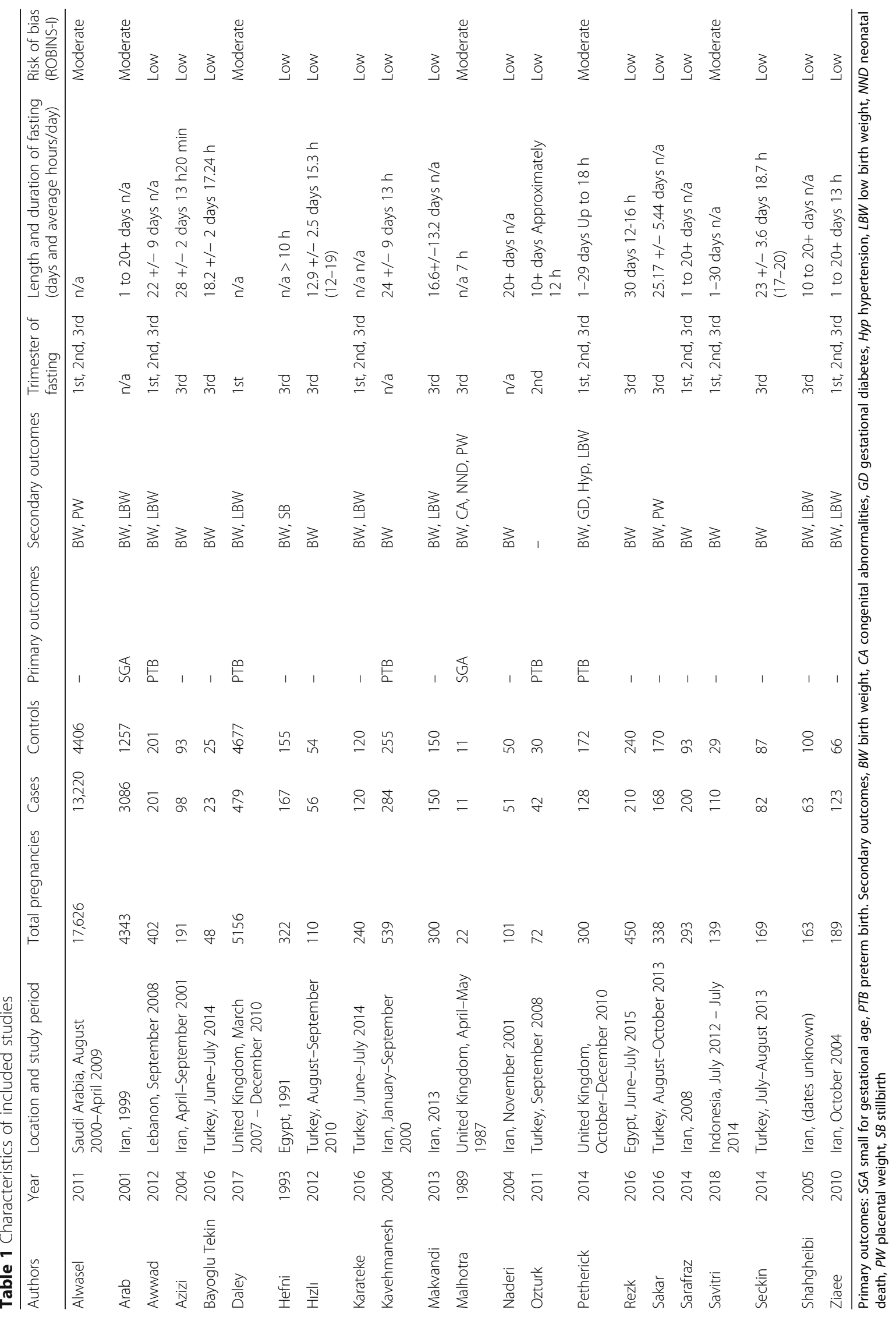


Table 2 Risk of bias of included studies

\begin{tabular}{|c|c|c|c|c|c|c|c|c|}
\hline \multirow{2}{*}{ Author } & \multirow[t]{2}{*}{ Year } & \multicolumn{7}{|l|}{ Bias domain } \\
\hline & & $\begin{array}{l}\text { Bias due to } \\
\text { confounding }\end{array}$ & $\begin{array}{l}\text { Bias in selection } \\
\text { of participants } \\
\text { into the study }\end{array}$ & $\begin{array}{l}\text { Bias in } \\
\text { classification } \\
\text { of exposure }\end{array}$ & $\begin{array}{l}\text { Bias due to } \\
\text { missing data }\end{array}$ & $\begin{array}{l}\text { Bias in measurement } \\
\text { of outcomes }\end{array}$ & $\begin{array}{l}\text { Bias in selection } \\
\text { of the reported } \\
\text { result }\end{array}$ & Overall \\
\hline Alwasel & 2011 & Low/Moderate & Low & Serious & Low & Low & Low & Moderate \\
\hline Arab & 2001 & Low & Low & Low & Serious & Low & Low & Moderate \\
\hline Awwad & 2012 & Moderate & Low & Low & Low & Low & Low & Low \\
\hline Azizi & 2014 & Low & Low & Low & Moderate & Low & Low & Low \\
\hline Bayoglu Tekin & 2016 & Low & Low & Low & Low & Low & Low & Low \\
\hline Daley & 2018 & Moderate & Low & Moderate & Moderate & Low & Low & Moderate \\
\hline Hefni & 1993 & Low/Moderate & Low & Low & Low & Low & Low/Moderate & Low \\
\hline Hizli & 2012 & Low & Low & Low & Low & Low & Low & Low \\
\hline Karateke & 2016 & Moderate & Low & Low & Low & Low & Low & Low \\
\hline Kavehmanesh & 2004 & Low/Moderate & Low & Low & Low & Low/Moderate & Low & Low \\
\hline Malhotra & 1989 & Moderate & Low & Low & Low/Moderate & Low & Low & Moderate \\
\hline Makvandi & 2013 & Moderate & Low & Low & Low & Low & Low & Low \\
\hline Naderi & 2004 & Moderate & Low & Low & Low & Low & Low & Low \\
\hline Ozturk & 2011 & Moderate & Low & Low & Low & Low/Moderate & Low & Low \\
\hline Petherick & 2014 & Moderate/Serious & Low & Moderate & Low & Low & Low & Moderate \\
\hline Rezk & 2016 & Low & Low & Low & Low & Low & Low & Low \\
\hline Sakar & 2016 & Low & Low & Low & Low & Low & Low & Low \\
\hline Sarafraz & 2013 & Low & Low & Low & Low & Low & Low & Low \\
\hline Savitri & 2018 & Low & Serious & Low & Low & Low & Low & Moderate \\
\hline Seckin & 2014 & Low & Low & Low & Low & Low & Low & Low \\
\hline Shahgheibi & 2005 & Low/Moderate & Low & Low & Low & Low & Low & Low \\
\hline Ziaee & 2010 & Low & Low & Low & Low & Low & Low & Low \\
\hline
\end{tabular}

Studies found to have a moderate or greater risk of bias in one or more domains are highlighted in bold

\section{Synthesis of results}

No studies presented data regarding perinatal mortality, and only two $[10,11]$ had data for SGA infants so meta-analysis was not performed. There was no significant effect of Ramadan fasting on the frequency of preterm delivery (OR 0.99, 95\% CI 0.72 to 1.37) (Fig. 2); data were available on 5600 pregnancies from five studies $[9,10,12,13,26]$ of which 1193 were exposed to Ramadan fasting. One study defined preterm delivery as $<38$ weeks gestation so these data were not included [27]. Another study excluded preterm deliveries from the cohort [28].

All but one study [9] examined birth weight as a continuous variable; data were available on 31,441 pregnancies, of which 19,030 were exposed to fasting. There was no significant effect of maternal Ramadan fasting on birth weight (SMD 0.03, 95\% CI 0.00 to 0.05) (Fig. 3). Three studies [29-31] presented mean results stratified by trimester in which fasting occurred, and an additional ten studies [11, 27, 32-39] were of third trimester exposure allowing a comparison to be performed; however no individual trimester showed a significant effect of fasting on birth weight and there was no difference between trimester groups $(p=0.99)$.

Eight studies $[10,13,26,30,31,35,39,40]$ investigated the effects of maternal fasting on low birth weight (LBW); there were 11,080 births from these studies, of which 4344 were from mothers who fasted. Fasting did not significantly affect the proportion of LBW babies (OR $1.05,95 \%$ CI 0.87 to 1.26 ) (Fig. 4). Three of these studies $[30,31,40]$ stratified their data by trimester $(n=2411$ first trimester fasting, $n=2571$ second trimester, $n=2356$ third trimester); there was no significant difference in the effect $\left(I^{2} 0.0 \% p=0.57\right)$.

Three studies comprising 17,986 pregnancies measured placental weight as an outcome [11, 29, 37]. Placental weight was significantly lower in fasting mothers (SMD -0.94, 95\% CI -0.97 to - 0.90) (Fig. 5).

Two authors were contacted for information. One responded [33], providing clarification on study outcomes. No information was provided regarding discrepancies between numbers in tables and text in another paper [40]; data from the text were used as these were consistent with data reported in the abstract. 


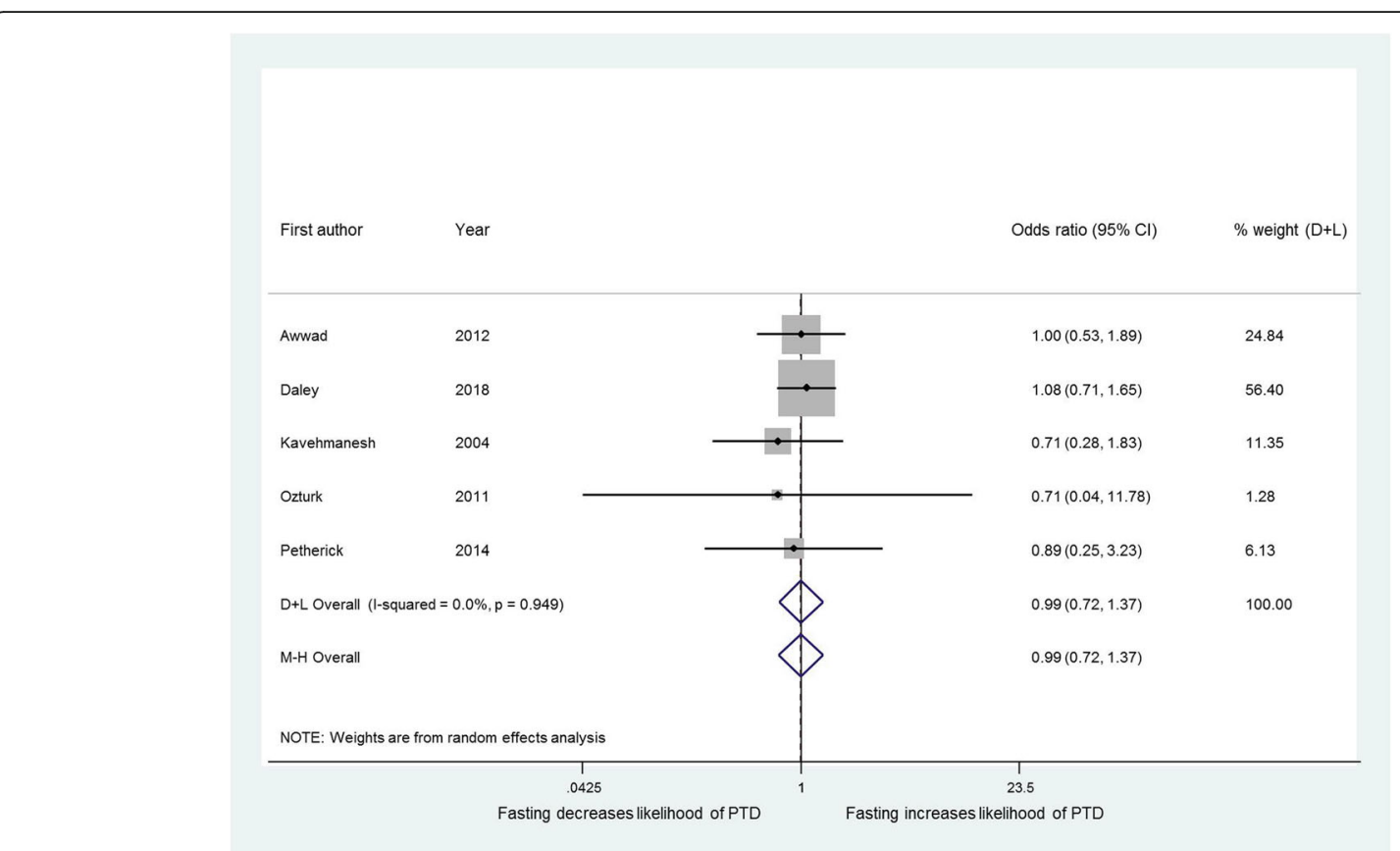

Fig. 2 Effect of fasting on the likelihood of preterm delivery. Forest plot showing the effect of maternal fasting on preterm delivery

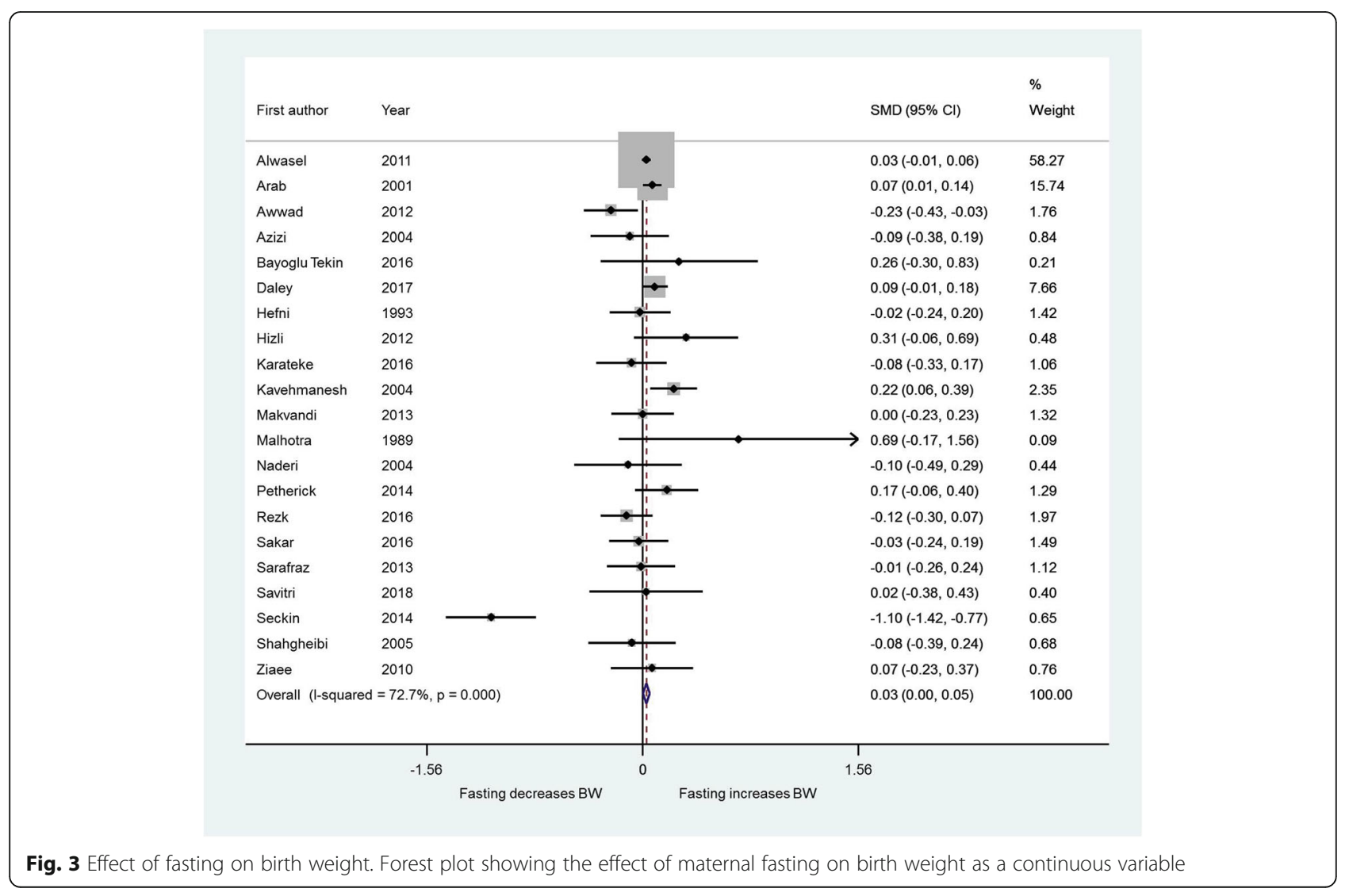




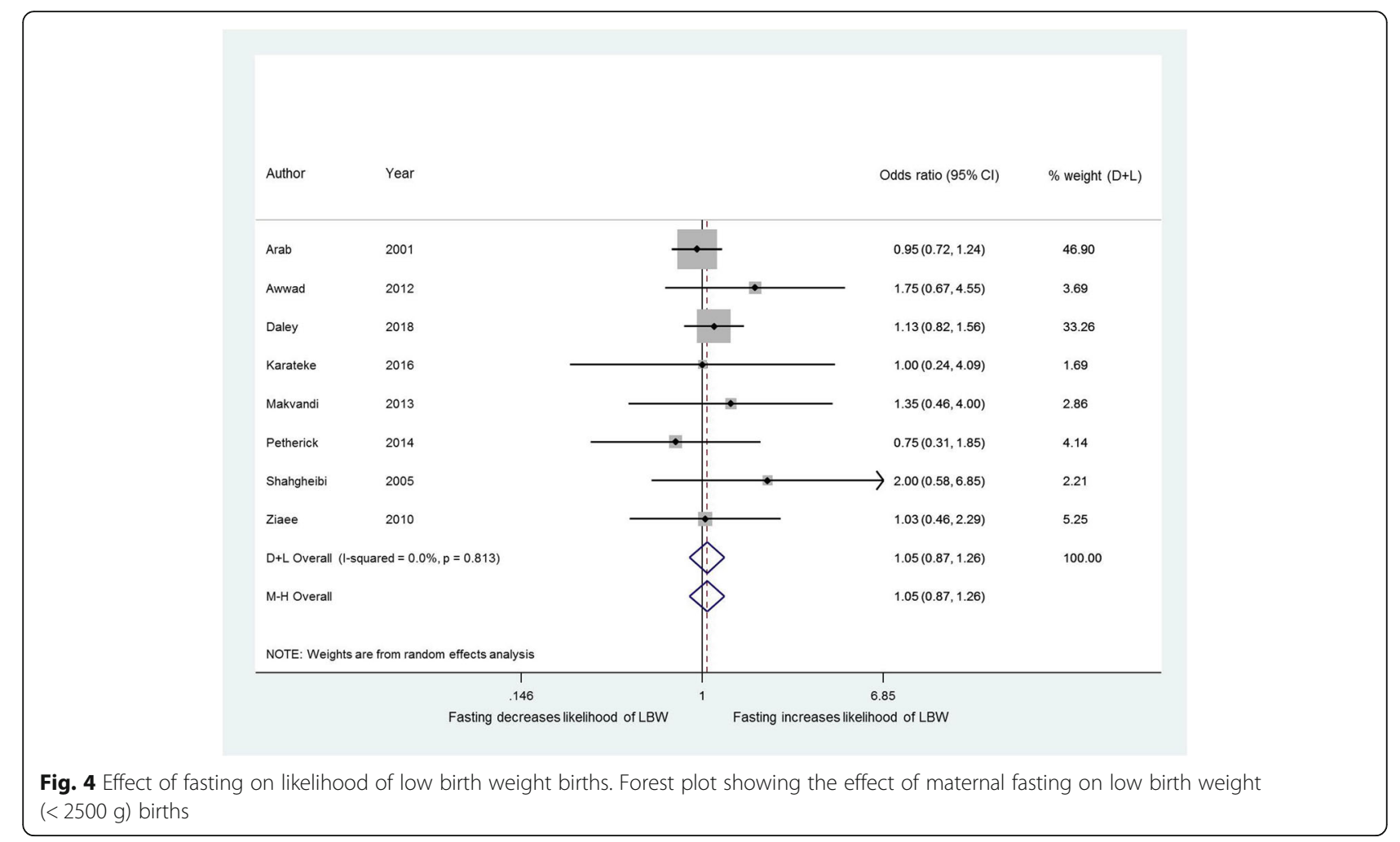

\section{Risk of bias of included studies}

Egger's test gave a value of $p=0.082$ indicating that there was no significant influence of small study effects on our results (Fig. 6). No studies were assessed as having a high risk of bias so the analyses presented include all results. However, of the 31,441 pregnancies where birth weight was measured as an outcome, 17,626 were from one study [29]. A sensitivity analysis was performed to determine how much of an effect this study had on the overall result; without this study a SMD of 0.03 (95\% CI -0.01 to 0.07 ) was obtained, still demonstrating no significant effect of fasting on birth weight.

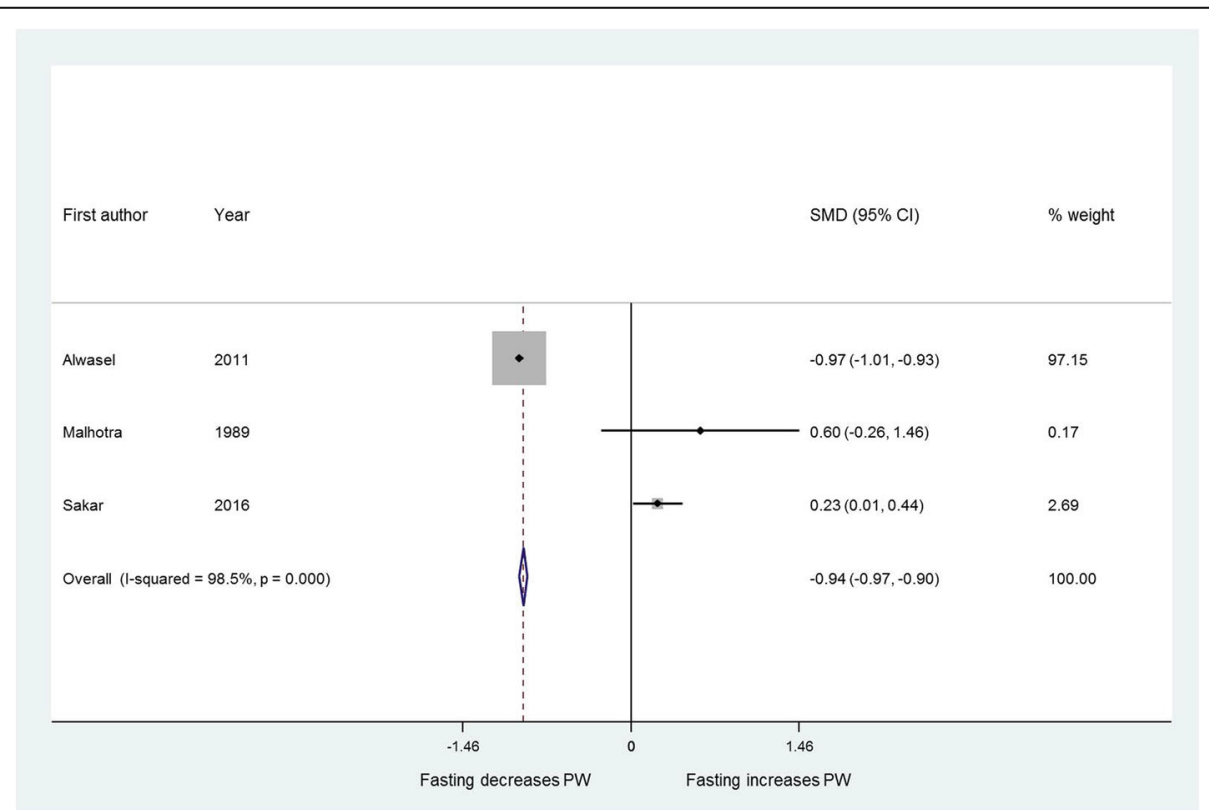

Fig. 5 Effect of fasting on placental weight. Forest plot showing the effect of maternal fasting on placental weight as a continuous variable 


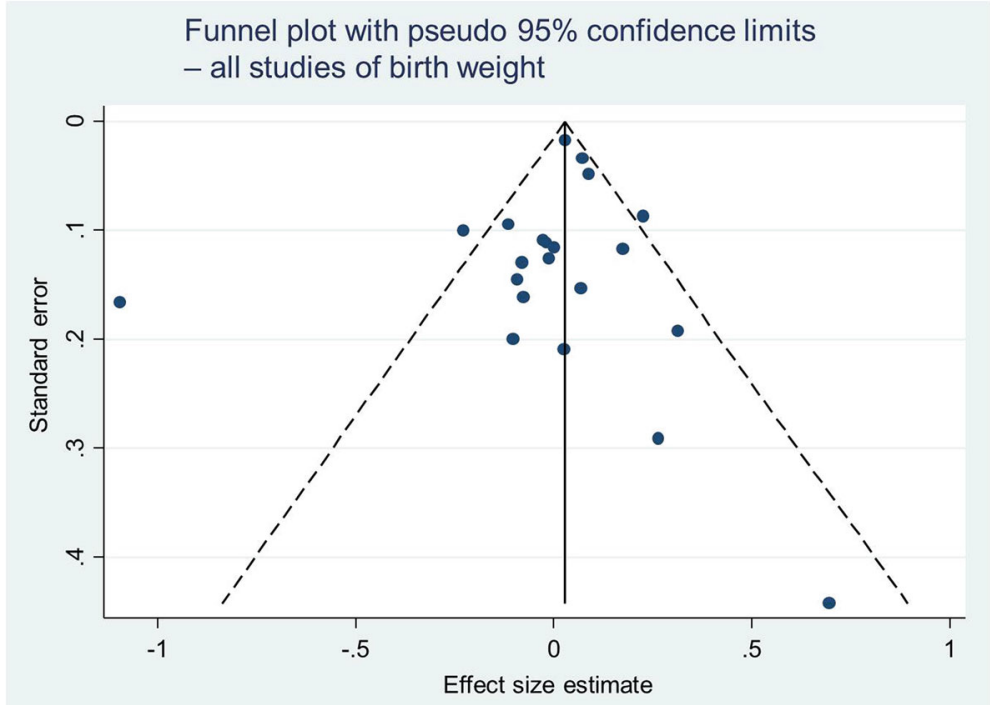

Fig. 6 Funnel plot with 95\% confidence limits. Funnel plot for all studies of birth weight

\section{Discussion}

Of our co-primary outcomes, only preterm birth had sufficient studies for meta-analysis which found no significant effect of Ramadan fasting. Data were available for some secondary outcomes: birth weight, placental weight and low birth weight; only placental weight was reduced by Ramadan fasting. However, this result was dominated by one study [29], which comprised 17,626 of 17,986 births for this outcome; one of the other two studies found a significant increase in placental weight [37]. There were insufficient data to perform meta-analysis for other outcomes, including: congenital abnormalities, gestational diabetes, hypertension, stillbirth and neonatal death. Stillbirth and neonatal death are arguably the most serious of these outcomes, yet due to the relatively small number of studies and their comparatively low incidences this study was underpowered to detect a difference. The paucity of data indicates a need for further large scale studies which report data on these rare but serious outcomes.

\section{Strengths and limitations}

This study was strengthened in that it was carried out in accordance with a prospective protocol with pre-specified eligibility criteria and primary outcomes. This is the first meta-analysis to examine the effects of Ramadan fasting and provides a dataset that can be updated as the number of studies grows. It has also highlighted the current lack of data and identified research gaps to be addressed. This study was limited by the fact that due to resources only English language papers were included. Furthermore, other potential effects of Ramadan fasting may not have been included in our outcome measures. Other studies have shown effects of Ramadan fasting on fetal movement
[41], maternal glucose levels [42] and various fetal growth indices [43]. Furthermore, our review did not examine whether fasting in the periconceptional period was associated with pregnancy outcome. As enduring effects of fasting and maternal undernutrition in this period have been shown in animal models $[44,45]$, this hypothesis merits further exploration.

The studies reviewed suggest that pregnant women who are well nourished may have nutritional reserves to support fetal adaptations during Ramadan fasting. However, longitudinal information on fetal growth was not available; the only feasible measure recorded was birth weight. Therefore, it remains to be established whether Ramadan fasting alters fetal growth patterns. Furthermore, there is little known about postnatal growth or growth and development in infancy and childhood.

Our literature search also identified papers that reported data on co-primary or secondary outcomes but presented the data in ways that could not be incorporated; Salleh [46] used linear regression to examine the effects of Ramadan fasting on birth weight and Boskabadi et al. [47] also looked at birth weight but presented data as medians and interquartile ranges; there was no control group in the study. One of our included studies [9] contained usable data for preterm delivery; however birth weight data were presented as medians and IQRs. Neither of these studies found differences between the control and fasting groups. Other studies were excluded because study groups were not sufficiently clear: Almond and Mazumder [48] acknowledged that not all women in their 'fasting' group fasted and that a large number of non-Muslims may also have been included. Cross et al. [49] defined maternal Muslim status (and 
assumed fasting status) based on the first three letters of maternal surnames.

Data showed significant heterogeneity for some outcomes. This variation may not relate to trimester of fasting, as when data were stratified by trimester there were no significant differences in the observed effect, although this may also represent a type 2 error as this meta-analysis may not have sufficient statistical power to detect such a difference. Only three studies presented usable data stratified by trimester of fasting for birth weight [29-31], of which one [31] found an association between trimester and mean neonatal weight. Alwasel et al. [29] showed significant associations in the second and third trimesters but not the first. Savitri et al. [28] performed regression analysis to investigate the effect of fasting trimester and found no significance, although they state that there was a trend towards lower birth weight with fasting, particularly in the second and third trimester. It may be that fasting later in pregnancy, when fetal growth is exponential, would be more likely to impact birth weight; further human studies are needed.

We were not able to investigate potential effects of Ramadan fasting length (in days) and duration (hours/ day) due to limitations in available data. Duration of fasting was not documented by all studies and data were recorded in different ways; some studies stated the average number of fasting hours per day $[9,12,32-34,36]$ while others gave the upper [13] or lower [27] limits. In total, 16 included studies recorded the average number of fasting days (Table 1), but few papers stratified by number of days fasting so meta-regression could not be performed. However, only one paper that divided data by number of fasting days [40] found a significant difference in outcome: that birth weight following more than 20 days of fasting was significantly greater than that after fasting for 1-9 days. Makki [50] found no relationship between the number of fasting days and incidence of low birth weight. However, this paper could not be included in our analysis as there was no comparator group.

Another potential source of heterogeneity was geographical location of study. The majority of studies were from Asia and the Middle East (8 from Iran [12, 31, 32, $35,39,40,51,52], 6$ from Turkey [9, 30, 33, 34, 37, 38], 2 from Egypt [27, 36], 1 from Indonesia [28], 1 from Saudi Arabia [29] and 1 from Lebanon [10]). Three included studies $[11,13,26]$ were from the UK. Geographical location may alter the number of hours of fasting, and thus the physiological challenge on the developing fetus, as the timing of the daily fast is determined by sunrise and sunset.

Risk of bias is unlikely to account for the observed heterogeneity as overall risk of bias of the included studies was low, with only six studies $[11,13,26,28,29,40]$ judged to be at moderate risk of bias. The majority of bias was due to uncertainty of the trimester affected by fasting. Three studies were judged to be at serious risk of bias for individual domains: one paper was due to missing data [40], another for selection of participants [28], and the other due to classification of exposure [29]. Therefore, subgroup analysis for risk of bias was not conducted.

\section{Conclusions}

This meta-analysis did not find any significant associations between Ramadan fasting and pregnancy outcome. Although studies were drawn from a large literature base, only a relatively small number met the inclusion criteria for analysis, limiting the breadth of robust conclusions. Until more definitive data are available, clinicians and other pregnancy healthcare providers cannot make firm recommendations that Ramadan fasting has no adverse consequences for mother or infant. Further observational studies of the effects of Ramadan fasting are required. Even if individual studies are not sufficiently large to determine differences in rare outcomes such as stillbirth or neonatal death, these should still be reported to facilitate subsequent meta-analysis. Additional studies are also needed to explore the origin of the considerable heterogeneity in observations; these should determine the effects of fasting in the periconceptional period, in different trimesters of pregnancy and whether geographical location, time of year and consequent duration of fasting alters the effect. Thus, well-designed studies investigating Ramadan fasting during pregnancy are needed to investigate the full impacts on maternal and fetal health, as well as to give potential fasting mothers an informed choice whilst addressing an issue that could have enduring public health consequences [53].

\section{Additional file}

Additional file 1: EMBASE search strategy. (DOCX 13 kb)

Abbreviations

Cl: Confidence interval; CINAHL: Cumulative Index of Nursing and Allied Health Literature; EMBASE: Excerpta Medica database; EThOS: E-thesis online service; HMIC: Healthcare Management Information Consortium; LBW: Low birth weight; MEDLINE: National Library of Medicine journal citation database; OR: Odds ratio; PROSPERO: International prospective register of systematic reviews; ROBINS-I: Risk of bias in non-randomised studies - of interventions; SGA: Small for gestational age; SMD: Standardised mean difference

\section{Acknowledgments}

None

Funding

None

Availability of data and materials

All data generated or analysed during this study are included in this published article and its supplementary information files. 


\section{Authors' contributions}

JDG, SH, SDS, DJLH, AEPH and NA contributed to the study concept and design. AEPH and DJLH wrote the protocol. SH and JW developed the search strategy. SH, SDS, DJLH and NA acquired the data for the study. DJLH and AEPH analysed and interpreted the data. JDG, NA, DJLH and AEPH developed the first draft of the manuscript and JDG, SH, SDS, DJLH, AEPH and NA revised all drafts and approved the final version. All authors read and approved the final manuscript.

\section{Ethics approval and consent to participate}

No ethical approval was required for this review as all data were already published in peer-reviewed journals.

\section{Consent for publication}

Not applicable

\section{Competing interests}

The authors declare that they have no competing interests

\section{Publisher's Note}

Springer Nature remains neutral with regard to jurisdictional claims in published maps and institutional affiliations.

\section{Author details}

${ }^{1}$ Maternal and Fetal Health Research Centre, Division of Developmental Biology and Medicine, Faculty of Biology, Medicine and Health, University of Manchester, 5th Floor (Research), St Mary's Hospital, Oxford Road, Manchester M13 9WL, UK. ${ }^{2}$ Trust Library, Central Manchester University Hospitals NHS Foundation Trust, Education South, Oxford Road, Manchester M13 9WL, UK. ${ }^{3}$ Division of Cardiovascular Sciences, Faculty of Biology, Medicine and Health, University of Manchester, 3rd Floor Core Technology Facility, 46 Grafton Street, Manchester M13 9NT, UK.

\section{Received: 20 July 2018 Accepted: 9 October 2018}

\section{Published online: 25 October 2018}

\section{References}

1. Arab M. Ketonuria and serum glucose of fasting pregnant women at the end of a day in Ramadan. Acta Med Iran. 2004;42:209-12.

2. Baynouna Al Ketbi LM, Niglekerke NJ, Zein Al Deen SM, Mirghani H. Diet restriction in Ramadan and the effect of fasting on glucose levels in pregnancy. BMC Res Notes. 2014;7:392.

3. Prentice AM, Prentice A, Lamb WH, Lunn PG, Austin S. Metabolic consequences of fasting during Ramadan in pregnant and lactating women. Hum Nutr Clin Nutr. 1983:37:283-94.

4. Pew Research Center. Religion \& Public Life Project: Muslim population by country. 2011. http://www.pewforum.org/2011/01/27/table-muslimpopulation-by-country/. Accessed 19 Dec 2014.

5. Barker DJ, Thornburg KL. The obstetric origins of health for a lifetime. Clin Obstet Gynecol. 2013;56:511-9.

6. Martin CL, Siega-Riz AM, Sotres-Alvarez D, Robinson WR, Daniels JL, Perrin EM, et al. Maternal dietary patterns during pregnancy are associated with child growth in the first 3 years of life. J Nutr. 2016;146:2281-8.

7. Sorensen HT, Sabroe S, Olsen J, Rothman KJ, Gillman MW, Fischer P. Birth weight and cognitive function in young adult life: historical cohort study. BMJ. 1997;315:401-3.

8. Siega-Riz AM, Herrmann TS, Savitz DA, Thorp JM. Frequency of eating during pregnancy and its effect on preterm delivery. Am J Epidemiol. 2001; 153:647-52.

9. Ozturk E, Balat O, Ugur MG, Yazicioglu C, Pence S, Erel O, et al. Effect of Ramadan fasting on maternal oxidative stress during the second trimester: a preliminary study. J Obstet Gynaecol Res. 2011;37:729-33.

10. Awwad J, Usta IM, Succar J, Musallam KM, Ghazeeri G, Nassar AH. The effect of maternal fasting during Ramadan on preterm delivery: a prospective cohort study. BJOG. 2012;119:1379-86.

11. Malhotra A, Scott PH, Scott J, Gee H, Wharton BA. Metabolic changes in Asian Muslim pregnant mothers observing the Ramadan fast in Britain. $\mathrm{Br}$ J Nutr. 1989;61:663-72.

12. Kavehmanesh Z, Abolghasemi H. Maternal Ramadan fasting and neonatal health. J Perinatol. 2004;24:748-50.
13. Petherick ES, Tuffnell D, Wright J. Experiences and outcomes of maternal Ramadan fasting during pregnancy: results from a sub-cohort of the born in Bradford birth cohort study. BMC Pregnancy Childbirth. 2014;14:335.

14. Roseboom TJ, van der Meulen JH, Ravelli AC, Osmond C, Barker DJ, Bleker OP. Effects of prenatal exposure to the Dutch famine on adult disease in later life: an overview. Mol Cell Endocrinol. 2001;185:93-8.

15. Savitri Al, Yadegari N, Bakker J, van Ewijk RJ, Grobbee DE, Painter RC, et al. Ramadan fasting and newborn's birth weight in pregnant Muslim women in the Netherlands. Br J Nutr. 2014;112:1503-9.

16. Thornburg KL, O'Tierney PF, Louey S. Review: the placenta is a programming agent for cardiovascular disease. Placenta. 2010;31:S54-9.

17. Alwasel SH, Abotalib Z, Aljarallah JS, Osmond C, Alkharaz SM, Alhazza IM, et al. Changes in placental size during Ramadan. Placenta. 2010;31:607-10.

18. British Nutrition Foundation. Ramadan and Pregnanacy. April 2015. https:// www.nutrition.org.uk/healthyliving/nutritionforpregnancy/ ramadanpregnancy.html. Accessed 17 Oct 2018.

19. Moher D, Liberati A, Tetzlaff J, Altman DG, Group P. Preferred reporting items for systematic reviews and meta-analyses: the PRISMA statement. PLoS Med. 2009;6:e1000097.

20. Sterne JA, Hernán MA, Reeves BC, Savović J, Berkman ND, Viswanathan M, et al. ROBINS-I: a tool for assessing risk of bias in non-randomised studies of interventions. BMJ. 2016:355:i4919.

21. StataCorp. STATA Statistical Software, release 14. College Station: StataCorp LP; 2015.

22. Harris R, Bradburn M, Deeks J, Harbord R, Altman D, Sterne J. Metan: fixedand random-effects meta-analysis. Stata J. 2008;8:3.

23. Sterne JA, Harbord RM. Funnel plots in meta-analysis. Stata J. 2004:4:127-41.

24. Higgins J, Thompson SG, Deeks JJ, Altman DG. Measuring inconsistency in meta-analyses. BMJ. 2003:327:557-60.

25. Deeks JJ, Higgins J, Altman DG. Analysing data and undertaking metaanalyses. Cochrane Handb Syst Rev Interv. 2008:243-96.

26. Daley A, Pallan M, Clifford S, Jolly K, Bryant M, Adab P, et al. Are babies conceived during Ramadan born smaller and sooner than babies conceived at other times of the year? A born in Bradford cohort study. J Epidemio Community Health. 2017;71:722-8.

27. Hefni M, Fikry S, Abdelkhalik M. Fasting in Ramadan and preterm labour. Saudi Med J. 1993;14:130-2.

28. Savitri Al, Amelia D, Painter RC, Baharuddin M, Roseboom TJ, Grobbee DE, et al. Ramadan during pregnancy and birth weight of newborns. J Nutr Sci. 2018;7:1-9.

29. Alwasel S, Abotalib Z, Aljarallah J, Osmond C, Alkharaz S, Alhazza I, et al. Secular increase in placental weight in Saudi Arabia. Placenta. 2011;32:391-4.

30. Karateke A, Kaplanoglu M, Avci F, Kurt RK, Baloglu A. The effect of Ramadan fasting on fetal development. Pak J Med Sci. 2015;31:1295-9.

31. Ziaee V, Kihanidoost Z, Younesian M, Akhavirad M-B, Bateni F, Kazemianfar $Z$, et al. The effect of Ramadan fasting on outcome of pregnancy. Iran J Pediatr. 2010:20:181-6.

32. Azizi F, Sadeghipour H, Siahkolah B, Rezaei-Ghaleh N. Intellectual development of children born of mothers who fasted in Ramadan during pregnancy. Int J Vit Nutr Res. 2004;74:374-80.

33. Bayoglu Tekin Y, Guvendag Guven ES, Mete Ural U, Yazici ZA, Kirbas A, Kir Sahin F. Evaluation of the effects of fasting associated dehydration on maternal NGAL levels and fetal renal artery Doppler parameters. J Matern Fetal Neonatal Med. 2016;29:629-32.

34. Hızlı D, Yılmaz SS, Onaran Y, Kafalı H, Danışman N, L M. Impact of maternal fasting during Ramadan on fetal Doppler parameters, maternal lipid levels and neonatal outcomes. J Matern Fetal Neonatal Med. 2012;25:975-7.

35. Makvandi S, Nematy M, Karimi L. Effects of Ramadan fasting on neonatal anthropometric measurements in the third trimester of pregnancy. J Fasting Health. 2013;1:53-7.

36. Rezk MA-A, Sayyed T, Abo-Elnasr M, Shawky M, Badr H. Impact of maternal fasting on fetal well-being parameters and fetal-neonatal outcome: a casecontrol study. J Matern Fetal Neonatal Med. 2016;29:2834-8.

37. Sakar M, Balsak D, Verit F, Zebitay A, Buyuk A, Akay E, et al. The effect of Ramadan fasting and maternal hypoalbuminaemia on neonatal anthropometric parameters and placental weight. J Obstet Gynaecol. 2016:36:483-6.

38. Seckin KD, Yeral MI, Karslı MF, Gultekin IB. Effect of maternal fasting for religious beliefs on fetal sonographic findings and neonatal outcomes. Int J Gynecol Obstet. 2014;126:123-5.

39. Shahgheibi S, Ghadery E, Pauladi A. Effects of fasting during the third trimester of pregnancy on neonatal growth indices. Ann Alquds Med. 2005;1:58-62. 
40. Arab M, Nasrollahi S. Interrelation of Ramadan fasting and birth weight. Med J Islamic Academy Sci. 2001;14:91-5.

41. Mirghani $H$, Weerasinghe D, Ezimokhai M, Smith J. The effect of maternal fasting on the fetal biophysical profile. Int J Gynecol Obstet. 2003;81:17-21.

42. Mirghani HM, Salem M, Weerasinghe SD. Effect of maternal fasting on uterine arterial blood flow. J Obstet Gynaecol Res. 2007;33:151-4.

43. Sakar MN, Gultekin H, Demir B, Bakir VL, Balsak D, Vuruskan E, et al. Ramadan fasting and pregnancy: implications for fetal development in summer season. J Perinat Med. 2015;43:319-23.

44. Rumball CWH, Harding JE, Oliver MH, Bloomfield FH. Effects of twin pregnancy and periconceptional undernutrition on maternal metabolism, fetal growth and glucose-insulin axis function in ovine pregnancy. J Physiol. 2008:586:1399-411.

45. Watkins AJ, Lucas ES, Wilkins A, Cagampang FRA, Fleming TP. Maternal periconceptional and gestational low protein diet affects mouse offspring growth, cardiovascular and adipose phenotype at 1 year of age. PLoS One. 2011;6:e28745.

46. Salleh H. Ramadan fasting among pregnant women in Muar district, Malaysia and its association to health outcomes. Malays J Reprod Health. 1989:7:69-83.

47. Boskabadi H, Mehdizadeh A, Alboumiri Z. Effect of the number of Ramadan fasting days on maternal and neonatal outcomes. J Fasting Health. 2014;2: 84-9.

48. Almond D, Mazumder BA. Health capital and the prenatal environment: the effect of Ramadan observance during pregnancy. Am Econ J Appl Econ. 2011;3:56-85.

49. Cross J, Eminson J, Wharton B. Ramadan and birth weight at full term in Asian Moslem pregnant women in Birmingham. Arch Dis Child. 1990;65: 1053-6.

50. Makki AM. Impact of Ramadan fasting on birth weight in 4 hospitals in Sana'a city, Yemen. Saudi Med J. 2002;23:1419-20.

51. Naderi T, Kamyabi Z. Determination of fundal height increase in fasting and non-fasting pregnant women during Ramadan. Saudi Med J. 2004;25:809-10.

52. Sarafraz N, Kafaei Atrian M, Abbaszadeh F, Bagheri A. Effect of Ramadan fasting during pregnancy on neonatal birth weight. J Fasting Health. 2014;2: $37-40$.

53. Susser $\mathrm{E}$, Ananth $\mathrm{CV}$. Is prenatal fasting during Ramadan related to adult health outcomes? A novel and important question for epidemiology. Am J Epidemiol. 2013;177:737-40.

Ready to submit your research? Choose BMC and benefit from:

- fast, convenient online submission

- thorough peer review by experienced researchers in your field

- rapid publication on acceptance

- support for research data, including large and complex data types

- gold Open Access which fosters wider collaboration and increased citations

- maximum visibility for your research: over $100 \mathrm{M}$ website views per year

At BMC, research is always in progress.

Learn more biomedcentral.com/submissions 